Referencia para citar este artículo: Robledo-Castro, C., Amador-Pineda, L. H., \& Ñáñez-Rodríguez, J. J. (2019). Políticas públicas y políticas educativas para la primera infancia: desafíos de la formación del educador infantil. Revista Latinoamericana de Ciencias Sociales, Niñez y Juventud, 17(1), 169-191. doi:https://dx.doi.org/10.11600/1692715x.17110

\title{
Políticas públicas y políticas educativas para la primera infancia: desafíos de la formación del educador infantil"
}

\author{
CARolina Robledo-CASTRo** \\ Profesora Universidad del Tolima, Colombia. \\ LUIS HERNANDO AMADOR-PINEDA*** \\ Profesor Universidad del Tolima, Colombia. \\ JoSÉ JULIÁN Ñ̈Á̃EZ-RODRÍGUEZ ${ }^{* * * *}$ \\ Profesor Universidad del Tolima, Colombia.
}

\section{Artículo recibido en abril 10 de 2018; artículo aceptado en agosto 17 de 2018 (Eds.)}

- Resumen (analítico): en este artículo se presentan los resultados de una investigación de carácter cualitativo, de tipo descriptivo-interpretativo, la cual correspondió a un análisis documental, cuyo objetivo fue identificar los retos emergentes a la formación del educador infantil que surgen de las políticas educativas nacionales e internacionales. A partir de un análisis de contenido de los textos de política, se exploraron las categorías axiales de políticas públicas, primera infancia y formación docente, ejercicio del que emergieron categorías y subcategorías en relación con los saberes que se esperan de un educador infantil: saberes generales, saberes pedagógicos, saberes didácticos y saberes transversales.

Palabras clave: política pública, política educativa, primera infancia, formación profesional, docente de preescolar, educación de la primera infancia (Tesauro de Ciencias Sociales de la Unesco).

\section{Public policies and educational policies for early childhood: Challenges of early childhood educator training}

- Abstract: The article presents the results of a completed investigation that was implemented using a qualitative descriptive-interpretative approach. This involved the authors conducting a document analysis, which had the purpose of identifying the challenges that emerge in the training

\footnotetext{
* $\quad$ En este artículo de investigación científica y tecnológica se presentan los resultados de la investigación denominada «Articulación de las políticas públicas educativas nacionales e internacionales con la formación de los pedagogos infantiles de la Universidad del Tolima», realizada entre agosto de 2015 y julio de 2017, financiada por la Universidad del Tolima y avalada por el Centro de Investigaciones de dicha universidad con el código 690115. Proyecto adscrito al Grupo de Investigación Desarrollo integral de la infancia. Área de conocimiento: Educación general. Subárea: Educación infantil.

** Psicóloga de la Universidad Católica de Pereira), especialista en Farmacodependencias de la Universidad Luis Amigó), y magíster en Desarrollo Humano y Educación (Cinde-Universidad de Manizales). Profesora de la Universidad del Tolima. Orcid: 0000-0002-8494-5305. Correo electrónico: crobledoc@edu.co

**** Licenciado en educación historia y geografía Universidad de Caldas. Magister en desarrollo educativo y social Cinde-Universidad pedagógica Nacional. Doctorado en educación Universidad de Salamanca. Orcid: 0000-0001-9462-6272. Índice H5: 3. Correo electrónico: lhamadorp@ ut.edu.co

**** Licenciado filosofía y educación religiosa Universidad Santo Tomás, Magister en Educación Universidad del Tolima; Candidato a Doctor en Ciencias de la Educación-Rudecolombia. Orcid: 0000-0002-1221-7050. Índice H5: 2. Correo electrónico: jjnanezr@ut.edu.co
} 
of early childhood educators that are the result of national and international educational policies. A content analysis explored the axial categories of public policies: early childhood and teacher training. As a result of the analysis categories and subcategories emerged in the knowledge expected from early childhood teachers: general knowledge, pedagogical knowledge, didactic knowledge and crosscutting knowledge.

Key words: Government policy, educational policy, early childhood, vocational training, preschool teachers, early childhood education (Unesco Social Science Thesaurus).

\section{Políticas públicas e políticas educacionais para a primeira infância: desafios da formação de professores na educação infantil}

- Resumo: o artigo apresenta os resultados de uma pesquisa concluída de natureza qualitativa, de tipo descritivo-interpretativo que corresponde a uma análise documental, sua finalidade foi identificar os desafios emergentes à formação dos pedagogos infantis que surgem desde as políticas educacionais nacionais e internacionais. A partir de uma análise de conteúdo dos textos de política, foram exploradas as categorias axiais de políticas públicas, primeira infância e formação de docentes, exercício do qual emergiram categorias e subcategorias em relação aos saberes que são esperados do educador infantil: saberes gerais, saberes pedagógicos, saberes da didática e saberes transversais.

Palavras-chave: política pública, política educativa, primeira infância, formação profissional, docente de educação pré-escolar, educação na primeira infância (Thesaurus de Ciências Sociais da Unesco).

\section{-1. Introducción. -2. Metodología. -3. Resultados. -4. Discusión. -Lista de referencias.}

\section{Introducción}

La formación del educador infantil ha transitado por múltiples transformaciones, propiciadas por acciones sociales, académicas, científicas, políticas y económicas, que hoy en día lo han posicionado como un tema de gran relevancia académica, en cuanto en este fenómeno confluye no solo el problema de la formación del maestro, sino que además dirige la mirada a los niños y niñas en sus primeros años de vida, así como el rol categórico que el educador tiene en el acompañamiento de su desarrollo integral temprano (Pérez-Escamilla, Rizzoli-Córdoba, Alonso-Cuevas, \& Reyes-Morales, 2017).

Frente a este panorama, en la presente investigación se ha propuesto problematizar «la formación del educador infantil en Colombia, a la luz de las políticas públicas y educativas que han emergido en los últimos años en el escenario nacional e internacional», para lo cual se han planteado los objetivos de 1) Identificar los retos emergentes a la formación del educador infantil a partir de las políticas educativas nacionales e internacionales; 2) Caracterizar los mecanismos de articulación desarrollados institucionalmente para responder a las dinámicas propiciadas por las políticas educativas estudiadas; 3) Impulsar la reflexión de actores involucrados en la formación de los educadores infantiles sobre dichas políticas, con el fin de adaptarlas a las demandas sociales, fortalecer su gestión y promover procesos de innovación educativa. En este artículo se muestran los resultados del primer objetivo de la investigación.

En gran parte de la bibliografía de la última década sobre la educación para la primera infancia se reconocen los primeros años de vida como un periodo clave en la consolidación del desarrollo integral del ser humano, determinante en el desarrollo posterior de la persona y de la sociedad. En el Congreso Mundial de la Primera Infancia (Organización de Estados Iberoamericanos, 2011) se advierte que las pruebas recogidas en los últimos años sobre el desarrollo infantil temprano (Myers, 2015; Pérez-Escamilla et al., 2017) han visibilizado y acentuado la importancia de una atención integral temprana, con una visión amplia que vincule otras disciplinas y contemple la infancia en un contexto 
cultural, histórico, ambiental y social complejo. Se ha dado lugar, además, al reconocimiento de los niños y las niñas «como agentes sociales cuya supervivencia, bienestar y desarrollo dependen de relaciones estrechas y se construyen sobre esa base» (ONU, 2005, p. 52), lo que implica trascender la noción de desarrollo infantil como un proceso de cambio psicológico individual, para comprenderlo como un «proceso que involucra la construcción social y política de los niños y las niñas» (Pineda-Báez, Garzón-Rodríguez, Bejarano-Novoa, \& Buitrago-Rodríguez, 2015, p. 272).

En las recientes metas educativas 2030 se destaca el papel protagónico de la atención y educación para la primera infancia, y se advierte que esta «pone los cimientos del aprendizaje a lo largo de la vida y favorece el bienestar de niños y niñas, y su preparación progresiva para el ingreso en la escuela primaria» (Unesco, 2015, p. 38), al tiempo que adjudica la responsabilidad de garantizar la salud, la protección frente a la violencia y la estimulación del desarrollo cognitivo, lingüístico, social, emocional y físico de los más pequeños. La educación infantil, además, brinda la oportunidad de identificar en forma temprana discapacidades y el riesgo de estas, de modo que la familia, la escuela y los servicios de salud puedan poner en marcha acciones oportunas que respondan a sus necesidades, reducir el impacto en su desarrollo, superar las barreras de aprendizaje, promover la inclusión y prevenir la marginación (Unesco, 2015).

En consecuencia, la atención y educación a la primera infancia se ha posicionado como un problema público, una prioridad en la agenda política nacional e internacional, y un derecho fundamental (Ancheta-Arrabal, 2008; Camargo-Abello, \& Castro-Rojas, 2013; Organización de Estados Iberoamericanos, 2011), «un componente integral y sistemático de las políticas de educación» ${ }^{1}$, que hace del desarrollo infantil temprano la base del capital humano de las naciones, de su desarrollo socioeconómico, y el pilar fundamental para cumplir con los objetivos de desarrollo sostenible (ODS) (Pérez-Escamilla, 2017).

Según Blanco (2012), las políticas orientadas a la atención integral a la primera infancia se convierten en un poderoso mecanismo para reducir las desigualdades, con alto retorno económico y social, siempre y cuando su formulación trascienda del enfoque de necesidades hacia uno de derechos, y garantice «una responsabilidad ética y legal del Estado para generar las condiciones que permitan garantizar su supervivencia, desarrollo, aprendizaje y protección» (Blanco, 2012, p. 6).

\section{Políticas públicas y educativas en la educación de la primera infancia: contextos nacional e internacional}

Las políticas públicas son dispositivos mediante los cuales «las autoridades públicas actúan, primero reconociendo problemas socialmente construidos en el seno de una comunidad, y luego, mediante la incorporación, programación y ejecución de acciones dirigidas a su solución o manejo» (Guzmán, citado por Rojas-Betancur, 2008, p. 889). Actúan como mecanismos para transformar la sociedad e impactar en forma específica la vida de los ciudadanos (Roth-Deubel, 2007) a través de la «designación de propósitos y programas de las autoridades públicas» (Castro-Rojas, Cuéllar-Argote, \& Londoño, 2012, p. 124), que implican la definición de metas y medios para su logro en el marco de una situación particular (Espinoza, 2009).

En este sentido, las políticas en materia de educación serían unas sucesivas tomas de posición del Estado frente a los problemas de la educación (Oszlak, \& O’Donnell, 1995), las cuales, según Zambrano-Leal (2012), han actuado históricamente como referentes normativos organizadores del sistema educativo al fijar un modelo particular de escuela, configurar una idea de infancia, definir derechos y obligaciones de los actores educativos, al tiempo que fijan principios regulativos de las instituciones de formación al integrar un sistema sofisticado de vigilancia y control (Grediaga-Kuri, 2011).

Las políticas educativas en América Latina describen la atención y educación de la primera infancia como base del desarrollo y aprendizaje integral de los niños y las niñas, y como condición

1 Koichiro Matsuura, director general de la Unesco. Presentación del Informe de Seguimiento de la Educación para Todos. Nueva York, 26 de octubre de 2006. 
fundamental para garantizar la calidad y equidad educativa (Unesco, 2016b). Estas políticas han dado prioridad a la lectura y escritura en los primeros grados, la educación inclusiva, los currículos de ciencias y tecnología para el desarrollo sostenible, el currículo y la educación para la ciudadanía mundial, que se caracterizan en seis tipos de políticas: sobre marcos regulatorios, de financiamiento, de fortalecimiento institucional, de aseguramiento de la calidad, de la oferta de desarrollo curricular, y las políticas para el desarrollo docente (Organización de Estados Iberoamericanos, 2013).

En relación con el campo académico de la política educativa en el contexto latinoamericano, Gorostiaga (2017) evidencia el predominio de un enfoque profesionalista en la formación del educador, enfoque que implica una preparación mayormente para la docencia, pero que muchas veces relega los debates epistemológicos, teóricos y metodológicos más generales dentro de las ciencias sociales, necesarios para la formación de educadores que aporten a la investigación y análisis de las políticas educativas.

Para el caso colombiano, tanto las políticas educativas como la de formación de maestros han surgido tradicionalmente de pronunciamientos internacionales que operan por lo regular desde una lógica estandarizada que desconoce las condiciones reales de los territorios, que se concretan en el ámbito nacional mediante normas que acaban por reproducir una forma homogeneizada de enseñanza, de sujeto de enseñanza y de saber pedagógico (Marulanda-Hidalgo, 2013; Rodríguez-Gómez, 2010). El desafío urgente es lograr que las políticas de formación de maestros trasciendan desde una lógica que estandariza y homogeneiza la profesionalización, hacia políticas que consideren la diversidad de agentes educativos, con igualdad ante las posibilidades de desarrollo (Blanco, 2012).

\section{Políticas públicas y educativas de primera infancia y los desafios para la formación del educador infantil en Colombia}

La emergencia de políticas encaminadas a mejorar la calidad de la educación se repite en una serie de retos para la formación de maestros, en especial del educador infantil. Este último es un agente crucial para la consecución de las metas trazadas en las políticas públicas y educativas de primera infancia (Unesco, 2015), lo que le demanda la necesidad de desarrollar nuevos conocimientos disciplinares que involucren el análisis y la comprensión de la realidad de la escuela (Navío-Gámez, 2007). Sin embargo, a pesar de que su formación se considera una apuesta clave para el desarrollo integral de la primera infancia (Carneiro-Sarturi, 2012; Castro-Rojas, 2008), esto no ha redundado en un mayor reconocimiento social de la labor del educador infantil ni en mejores oportunidades para su desenvolvimiento profesional. Del docente de educación infantil se espera que logre «impulsar los procesos para generar las competencias y capacidades humanas que se consideran indispensables para el crecimiento económico, el bienestar social y el desarrollo individual» (Hargreaves, citado por Moreno, 2006, p. 3), sin que necesariamente se le brinden las condiciones para su propio desarrollo; a esto se suma una extendida desconfianza política y pública en los sistemas de formación docente, a los cuales Colombia destina apenas el $1 \%$ del gasto anual de educación (Moreno-Olmedilla, 2006).

A juicio de Fuentes de la Roa (2008), la atención integral a la primera infancia, como asunto de política pública, es una prioridad y un factor de garantía de calidad del componente pedagógico, en el que los educadores cumplen un papel de mediadores para que los derechos de la infancia tengan lugar en los escenarios donde transcurre la vida de los niños y las niñas. Por tanto, la formación del maestro «se convierte en un tema neurálgico dentro de la formulación de la política pública de primera infancia» (Fuentes de la Roa, 2008, p. 70). En palabras de Simarra-Torres (2010), «no es posible mejorar la calidad de la educación sin mejorar prioritaria y sustancialmente la calidad profesional de quien enseña» (p. 49); el desafío que plantea esta tensión es el reconocimiento ineludible de la formación superior de docentes para la primera infancia (Blanco, 2012), por cuanto mejorar sus posibilidades de formación y sus condiciones se convierte en una urgencia para las políticas educativas latinoamericanas (Ávalos, 2007), tarea posible siempre y cuando intervengan todos los actores que inciden en la estructuración y organización de estas. 
Tal cual como lo señala la Unesco (2016a), «el progresivo reconocimiento de la educación para la primera infancia hace imperativo que las políticas para fortalecer el estatus se orienten a la profesionalización de sus docentes, cuestión que supone implementar condiciones laborales que les permitan enfrentar las complejas demandas que se les hacen a sus prácticas pedagógicas» (p. 117); para esto es indispensable difundir entre los actores de la sociedad la relevancia y complejidad de la educación infantil, y hacer énfasis en la formación especializada de alto nivel, como factores claves para la calidad de la educación y el desarrollo de la sociedad.

La idea es apostar por fortalecer el campo profesional de la educación para la primera infancia con criterios que impulsen una agenda y políticas fundamentadas en un crecimiento con calidad, garantizar condiciones materiales y simbólicas específicas, y así lograr el posicionamiento a partir de la fuerte convicción de que el empoderamiento y la autonomía de un campo profesional del educador infantil se sustentan en una base de conocimiento común, muy especializado, construido y legitimado participativamente por sus miembros (Unesco, 2016a).

Uno de los propósitos trazados para las metas educativas 2030 es «formular políticas, estrategias y planes de acción claros para la profesionalización del personal de la atención y educación para la primera infancia, mediante la mejora y el seguimiento de su desarrollo profesional permanente, su situación y sus condiciones de trabajo» (Unesco, 2015, p. 54). Esto último exige avanzar hacia la configuración de escenarios preparatorios para el ejercicio profesional que permitan a los futuros docentes ampliar su dominio sobre lo que entraña y demanda la educación infantil en el marco de una atención integral, como ha sido la perspectiva que Colombia ha venido desarrollando (BuitragoRodríguez, 2015).

Históricamente, la formación del educador infantil en Colombia ha generado diferentes posicionamientos en la agenda política. Fuentes de la Roa (2008) destaca el papel de la mesa de talento humano en el marco de la construcción de la Política Nacional para la Primera Infancia, en la cual se concretó la política de formación a través del Sistema de Formación para Educadores que atienden a la primera infancia, en respuesta al artículo 29 de la Ley 1098 de 2007, en el que se establecen acuerdos y compromisos para que dicho proceso de formación sea prioritario y redunde en la calidad de la atención. El sistema es un conjunto de conceptos, lineamientos y estrategias, y actúa como política que orienta acciones de planes y programas de formación alrededor de un objetivo común: construcción de saberes enfocados en favor del desarrollo humano integral de la primera infancia. Sin embargo, en el Informe Nacional sobre Docentes para la Educación de la Primera Infancia en Colombia (Buitrago-Rodríguez, 2015), iniciativa liderada por la Unesco, se mencionan puntos álgidos que hay que reconfigurar en los sistemas de formación de maestros, y se encontró que solo el $19 \%$ de los docentes de educación inicial y el $59 \%$ de los de preescolar cuentan con formación de pregrado, y con posgrado apenas un $1 \%$ y un $24 \%$, respectivamente.

\section{Políticas públicas y políticas educativas nacionales e internacionales}

Con esta investigación se pretende problematizar la formación del educador a la luz de las políticas tanto de formación docente como de atención y educación a la primera infancia, entre las cuales se destacan a escala internacional la Declaración mundial «Educación para todos» (Unesco, 1990), la Cumbre mundial en favor de la infancia (Unicef, 1990), las Metas del milenio (Unesco, 2000), la Observación general número 7 de la Convención sobre los Derechos del Niño respecto a los derechos de la primera infancia (ONU, 2005), las Metas educativas 2021 (Organización de Estados Iberoamericanos, 2008) y la Agenda de educación 2030 (Unesco, 2015).

Después de tales políticas se han hecho pronunciamientos nacionales: el Código de Infancia y Adolescencia (Ley 1098) (Congreso de Colombia, 2006), el Plan Nacional Decenal de Educación 20062016 (Ministerio de Educación Nacional, 2006) y el actual Plan Nacional 2016-2026, la Estrategia Nacional de Atención Integral a la Primera Infancia, la política pública nacional «Colombia por la primera infancia» (Conpes 109) (Departamento Nacional de Planeación, 2007), la serie Lineamientos 
curriculares del preescolar del Ministerio de Educación Nacional (1998), el Sistema Nacional de Formación de Educadores y Lineamientos de Política (Ministerio de Educación Nacional, 2014b), el Decreto único reglamentario 1075 del sector de la educación (Ministerio de Educación Nacional, 2015a), los derechos básicos de aprendizaje para preescolar (Ministerio de Educación Nacional, 2016a) y la Ley 1804, política de Estado para el desarrollo integral de la primera infancia «De cero a siempre» (Congreso de Colombia, 2016). A esta discusión se unen los nuevos lineamientos de calidad para la obtención y renovación de registro calificado, contenidos en el Decreto 2450 (Ministerio de Educación Nacional, 2015a), y la Resolución 2041 (Ministerio de Educación Nacional, 2016b), que formulan lineamientos claves para los programas de formación de maestros.

\section{Metodología}

La investigación se orienta desde un paradigma histórico-hermenéutico, de enfoque cualitativo, que corresponde a un estudio de tipo descriptivo-interpretativo, en el que se utilizó el análisis documental como estrategia de indagación. En palabras de Alfonzo (1994), la investigación documental es un proceso sistemático de indagación, recolección, organización, análisis e interpretación de información en torno a un tema específico; se caracteriza por la revisión directa o indirecta de documentos, para lo cual se integró la matriz de análisis documental como instrumento de análisis de información.

Las unidades de análisis correspondieron a los textos de políticas públicas y educativas nacionales e internacionales recolectados y seleccionados en relación con las dos categorías de trabajo: 1) Educación de la primera infancia en el marco de la atención y desarrollo integral, y 2) Formación del educador infantil. Como estrategia de análisis se implementó el análisis de contenido, entendido este, en palabras de Andréu-Abela (2000), como una técnica de interpretación de textos independientemente de su tipo de registro, con la premisa de que todo contenido de un texto alberga sentidos, los cuales pueden interpretarse para dar lugar a la comprensión de diferentes fenómenos sociales. Esta clase de análisis se basa en particular en la lectura sistemática, objetiva, reproducible y válida, que combina intrínsecamente la observación, la producción de datos, la interpretación y el análisis de datos (Fernández-Chávez, 2002).

Tras el rastreo y la recopilación de textos de políticas públicas y educativas nacionales e internacionales, se seleccionaron siete políticas (figura 1) a partir de los criterios de pertinencia, representatividad y vigencia, en función de las categorías axiales de la investigación.

Figura 1. Textos de políticas educativas seleccionadas

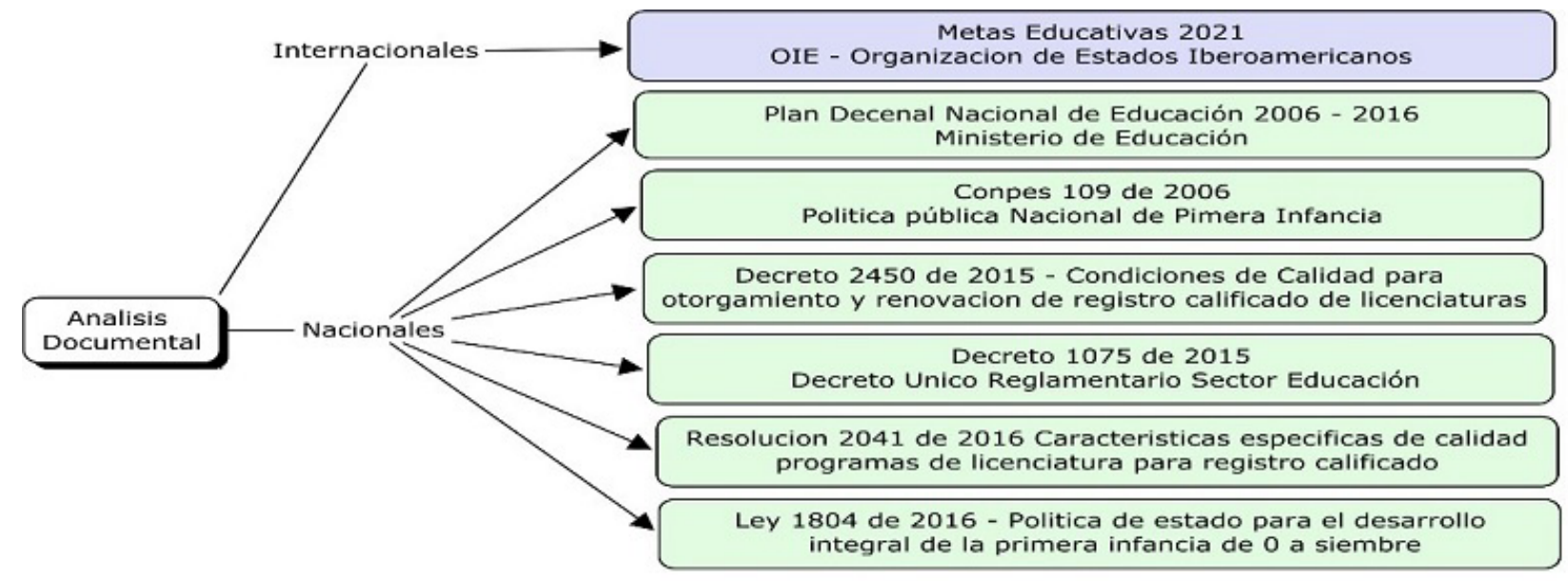




\section{Resultados}

Los textos de las políticas fueron objeto de un análisis de contenido. Para López (2002), se trata de un conjunto de instrumentos metodológicos, aplicados a los discursos (contenidos) diversificados, que va desde el cálculo de frecuencias hasta la extracción de estructuras que configuran modelos. Actúa como una hermenéutica controlada, basada en la deducción, en la inferencia, por lo que invita al investigador a «la atracción por lo oculto, lo latente, lo potencial inédito, lo no dicho» (López, 2002, p. 173).

Este análisis, que se respaldó en el software de análisis cualitativo Atlas.ti, versión 7, dio como resultado una serie de categorías emergentes alrededor de los saberes del educador infantil, categorías orientadas que permitieron identificar los retos emergentes a la formación del educador infantil a partir de las políticas educativas nacionales e internacionales, y que se agruparon en cinco macrocategorías: «Saberes generales», «Saberes disciplinares», «Saberes pedagógicos», «Saberes didácticos»y «Saberes transversales» (figura 2). Los resultados se presentan a partir de figuras en las que se recogen algunas de las unidades de contenido analizadas, en las cuales se reconoce cómo en cada política educativa se contemplan los saberes del educador infantil.

Figura 2. Categorías emergentes alrededor de los saberes del educador infantil
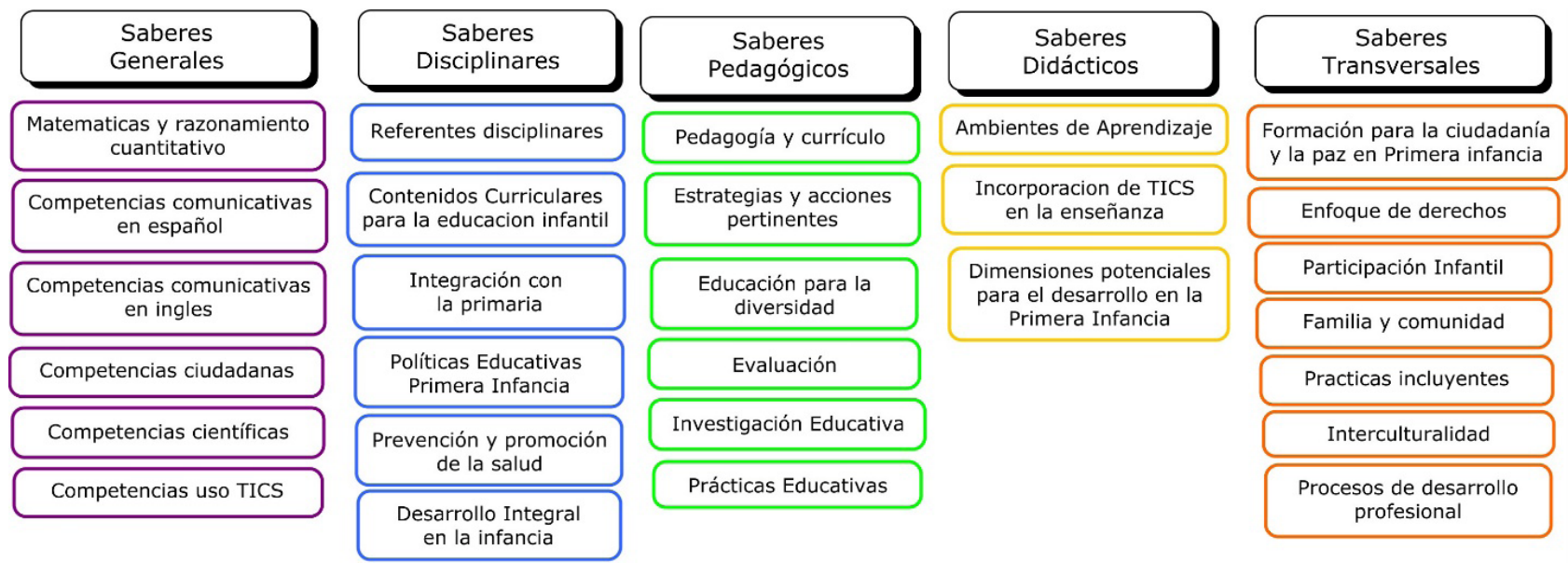

La categoría «Saberes generales» se contempla en la Resolución 2041 (Ministerio de Educación Nacional, 2016b), según la cual se espera que cada docente, en su formación inicial y continuada, logre desarrollar un nivel básico y suficiente de competencias matemáticas, comunicativas —en español y en inglés-, científicas, ciudadanas y en el uso de las TIC.

\section{Saberes disciplinares}

De acuerdo con la Resolución 2041 (Ministerio de Educación Nacional, 2016b), el educador debe formarse en saberes específicos que le permitan «consolidar un dominio de los saberes y conocimientos actualizados de los fundamentos conceptuales y disciplinares del campo o el área en que se desempeñará como licenciado» (p. 5), de modo que consiga incorporar a su quehacer docente la trayectoria histórica y los fundamentos epistemológicos del campo disciplinar o saberes específicos que estructuran su programa de formación.

Del análisis hecho se identificaron seis categorías o ejes asociados a los saberes disciplinares del educador infantil (figura 3): «Referentes disciplinares», «Articulación de la educación infantil con la primaria», «Conocimientos sobre las políticas para la primera infancia», «Prevención y promoción de la salud», «Desarrollo integral»y «Currículo pertinente para la educación infantil». 
Figura 3. Categoría «Saberes generales»

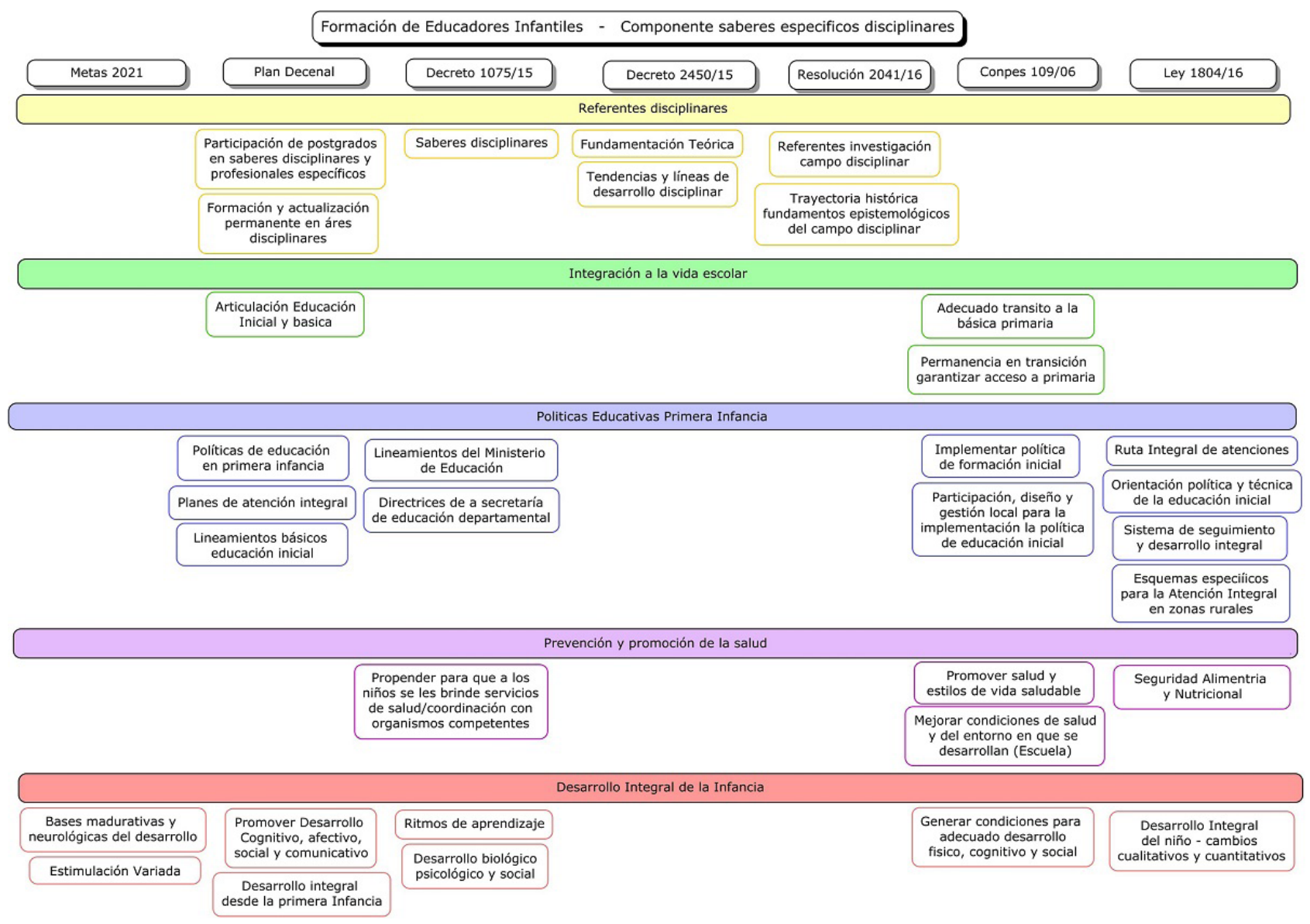

Respecto al eje «Referentes disciplinares», en el Decreto 2450 (Ministerio de Educación Nacional, 2015a) se destacan la importancia de la fundamentación teórica, las tendencias y las líneas de desarrollo disciplinar, en tanto que en la Resolución 2041 (Ministerio de Educación Nacional, 2016b) se enfatiza en la trayectoria histórica, los fundamentos epistemológicos y la investigación del campo disciplinar; a su vez, en el Plan Decenal y el Decreto 1075 se contemplan aspectos asociados al desarrollo profesional, dignificación y formación de docentes, la actualización permanente y la participación en posgrados en saberes disciplinares y profesionales específicos.

Las políticas de primera infancia exigen el compromiso y la participación de toda la ciudadanía en forma activa, individual y colectiva como reto a la construcción de un proyecto político de país en gesta y transformación social y cultural. En el Plan Decenal de Educación se hizo hincapié en la necesidad de que el docente desarrolle saberes específicos que le permitan desempeñar un rol activo con respecto a estas. Al docente se le demanda la comprensión teórica y la capacidad de integrar en sus prácticas educativas los principios de estas políticas, explicitar las intenciones y acciones de los actores implicados, entre ellos el del educador infantil, en lógica estructural del Estado, y orientado a configuraciones institucionales en oportunidad y desarrollo de lo humano.

Esto supone, entre los desafíos del educador infantil, una claridad y una actualización permanente con respecto a la emergencia de dichas políticas y lineamientos de política, la capacidad de integrarlas en los planes de atención integral y los lineamientos básicos de educación inicial, y como se enfatiza en el Conpes 109, la participación del docente en el diseño e implementación de las políticas de formación infantil. La Ley 1804 coincide con la implementación de rutas de atención integral mediante 
una orientación política y técnica en un sistema de seguimiento y desarrollo integral en el que han de incluirse esquemas específicos para la atención integral en zonas rurales.

La atención integral tiene como propósito conseguir que la infancia alcance su máximo potencial de desarrollo, pues al ser los niños y las niñas sujetos titulares de los derechos, la corresponsabilidad del Estado, la sociedad y la familia es garantizarles el ejercicio pleno de ellos. Entre los derechos impostergables de la primera infancia están la atención en salud y nutrición, el esquema completo de vacunación y la protección contra los peligros físicos. El educador infantil tiene una implicación notable en la prevención y promoción de la salud, como se expresa en el Conpes 109; la incorporación de la promoción de hábitos y estilos de vida saludables que permitan mejorar las condiciones de salud y del entorno donde los niños y las niñas se desarrollan, entre ellos la escuela; la garantía de servicios de salud con el apoyo y la coordinación de los programas por parte de organismos competentes para tal fin (Decreto 1075), y la seguridad alimentaria y nutricional de la infancia (Ley 1804).

La transición de la educación infantil al contexto escolar es una de las experiencias más importantes y demandantes de la infancia: cambios en las relaciones interpersonales, estilo de enseñanza, ambiente, tiempos, contextos de aprendizaje y el aprendizaje mismo (Fabián \& Dunlop, 2006), que suele ir acompañada de expectativas crecientes sobre lo que los niños y las niñas deben saber y ser capaces de hacer (Unesco, 2015); por consiguiente, es necesario promover buenas prácticas en los procesos de articulación con la básica primaria: actividades que favorezcan el aprendizaje y apoyen el bienestar socioemocional, y procesos que garanticen una comunicación fluida y de calidad entre padres y maestros.

Para la Unesco (2000), una transición adecuada a la vida escolar contribuye al posterior éxito académico y social de los niños y las niñas. Con el Conpes 109 y el Plan Decenal se pretende fortalecer la articulación interinstitucional e intersectorial que permita el adecuado tránsito entre la educación inicial y la básica primaria, con el objeto de garantizar la permanencia y retención en el sistema educativo.

La acción educativa para la infancia se sustenta en las bases madurativas y neurológicas del desarrollo y en una estimulación variada para este fin (Metas 2021). El eje «Desarrollo integral en la infancia» se refiere a la necesidad de contemplar los ritmos de aprendizaje y el desarrollo biológico y social como ejes referentes de la formación (Decreto 1075); promover el desarrollo integral e interrelacionarlo con las dimensiones cognitiva, comunicativa, afectiva, social y comunicativa (Plan Decenal), y generar espacios y condiciones que tomen como base los cambios cuantitativos y cualitativos durante la infancia (Conpes 109, Ley 1804).

A este propósito sigue la discusión sobre el «Currículo pertinente para la primera infancia», como lo expresan Zapata-Ospina y Restrepo-Mesa (2013): «En este proceso, el niño juega un papel activo, donde sus intereses y necesidades se ponen en juego con los intereses sociales, culturales, políticos y económicos del entorno en el que habita, colocándose permanentemente en discusión la relevancia de los aprendizajes que es preciso promover y desarrollar desde la infancia» (p. 218). Las políticas revisadas coinciden en la necesidad de contextualizar los contenidos curriculares en relación con las características culturales, la formación para la paz, el bilingüismo y el uso de las TIC, además de que hacen hincapié en el juego y la expresión artística como componentes centrales de los currículos en primera infancia (Ley 1804), sumados a la literatura y la exploración del medio (figura 4). 
Figura 4. Contenidos curriculares en la educación infantil

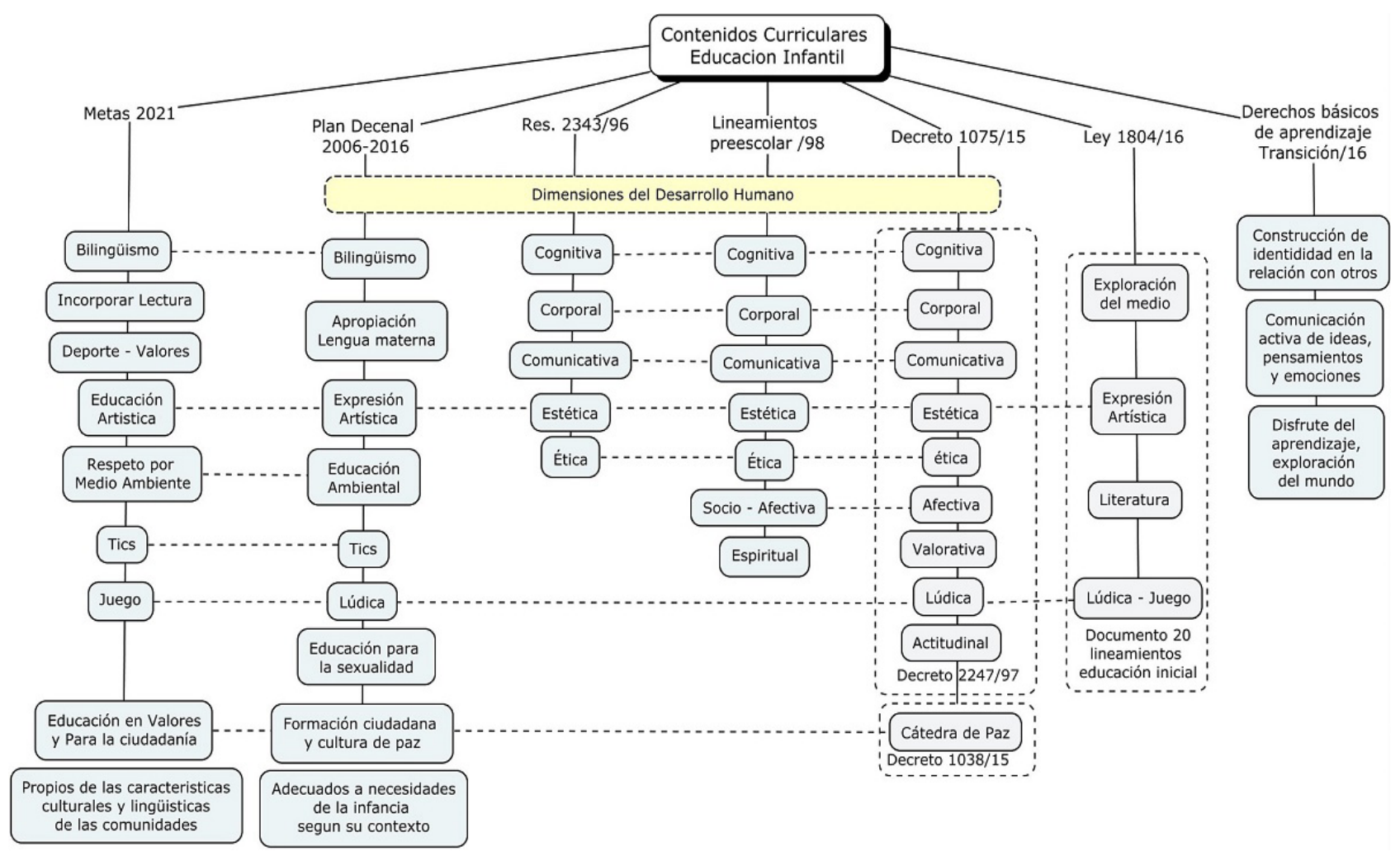

Los documentos que se adicionaron al análisis de esta categoría fueron los siguientes:

- El Decreto 2247 de 1997, que determina los objetivos, principios y contenidos curriculares para la primera infancia, al igual que las características básicas curriculares del nivel preescolar, y describe el currículo como un proyecto en permanente edificación que posibilita la construcción investigativa y pedagógica.

- La Resolución 2343 de 1996, que establece para la educación primara y básica, indicadores de logros fijados a partir de áreas obligatorias y fundamentales definidas en la Ley 115 (Congreso de Colombia, 1994), y determina para preescolar indicadores formulados desde las dimensiones del desarrollo humano: corporal, cognitiva, comunicativa, estética y ética.

- Los lineamientos curriculares y pedagógicos para la educación preescolar (Ministerio de Educación Nacional, 1998), que incluyen las recomendaciones de Jacques Delors en Jomtien (Unesco, 1990), buscan generar procesos de reflexión, análisis crítico y ajustes progresivos en las comunidades educativas. Estos lineamientos contemplan como aprendizajes fundamentales: aprender a conocer, aprender a hacer, aprender a vivir juntos y aprender a ser, y establece como dimensiones del desarrollo integral: socioafectiva, corporal, cognitiva, comunicativa, estética, espiritual y ética.

- A partir del documento base para la construcción de lineamientos pedagógicos y curriculares para la educación inicial (Ministerio de Educación Nacional, 2012), el Ministerio de Educación Nacional propició un ejercicio participativo en diferentes regiones del país, lo que dio como resultado una serie de documentos con orientaciones pedagógicas, encaminados a favorecer la calidad de la educación inicial y la cualificación del talento humano vinculado a la atención integral (Ministerio de Educación Nacional, 2014a, 2014c). 
Las políticas estudiadas muestran como principios orientadores de la educación infantil la lúdica, la literatura, el juego y las actividades recreativas, reafirmados en la Ley 1804, y en consonancia con las demás políticas, se adicionan bilingüismo, deporte, arte, lenguaje y exploración del medio ambiente, como pilares determinantes para formar habilidades de interacción y la preparación para la vida social. En sintonía con estos, el Ministerio de Educación Nacional (2016a) determina los derechos básicos de aprendizaje para transición, definiéndolos como «un conjunto de aprendizajes estructurantes que construyen las niñas y los niños a través de las interacciones que establecen con el mundo, con los otros y consigo mismos, por medio de experiencias y ambientes pedagógicos en los que están presentes el juego, las expresiones artísticas, la exploración del medio y la literatura» (p. 5).

\section{Saberes pedagógicos}

En esta macrocategoría se han agrupado las categorías emergentes asociadas a los conocimientos y saberes que respaldan el ejercicio de enseñanza-aprendizaje del maestro. Para la Resolución 2041, el educador debe desarrollar en su formación «la capacidad de utilizar conocimientos pedagógicos y de las ciencias de la educación que permitan crear ambientes para la formación integral y el aprendizaje de los estudiantes» (Ministerio de Educación Nacional, 2016b, p. 5). De estos conocimientos forman parte las tendencias pedagógicas, la comprensión del contexto, las características y diferentes maneras de aprender de las niñas y los niños, la importancia del desarrollo humano y cultural de los estudiantes en las prácticas educativas, la capacidad de comprender, reflexionar, hacer seguimiento y tomar decisiones sobre los procesos de formación, la autorregulación y planeación de acciones de mejora en los procesos educativos y el currículo.

De conformidad con las orientaciones pedagógicas para la educación inicial dadas por el Ministerio de Educación Nacional (2014c), «la educación inicial se lleva a cabo desde una pedagogía que reconoce las diferencias y que se piensa en clave de derechos» (p. 48). En esta perspectiva, la pedagogía en la educación infantil se entiende como un saber teórico-práctico en permanente elaboración por parte del docente, retroalimentado por la reflexión sobre su práctica educativa y con los fundamentos teóricos elaborados hasta el momento. Esta categoría dio como resultado los siguientes ejes o subcategorías: «Pedagogía y currículo», «Estrategias y acciones», «Prácticas educativas», y «Evaluación, investigación y educación para la diversidad» (figura 5). 
Figura 5. Categoría «Saberes pedagógicos»

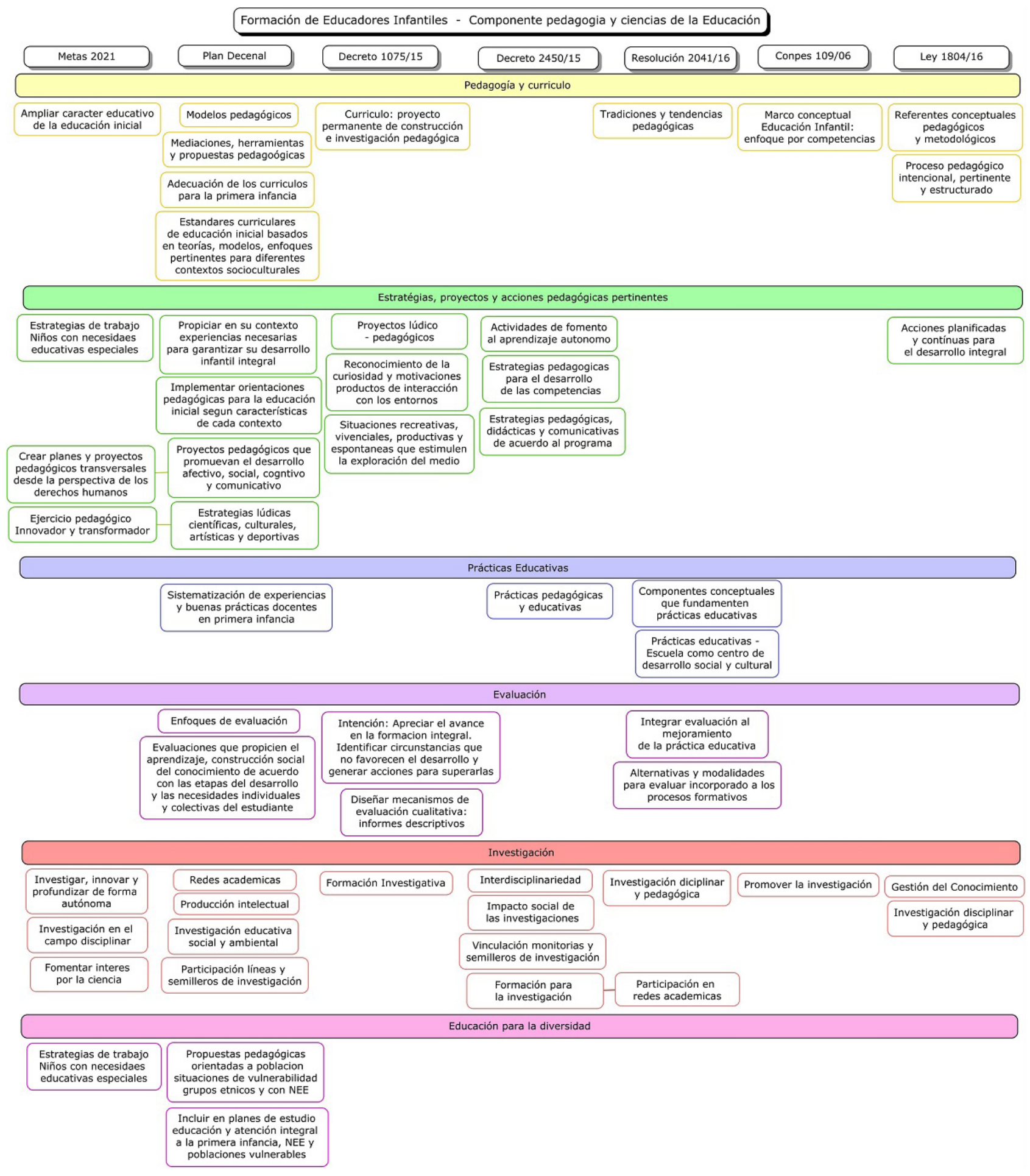

En el eje «Pedagogía y currículo» se retoma el propósito de los países iberoamericanos en las Metas 2021 de ampliar y garantizar el carácter educativo de la educación infantil, de modo que las acciones pedagógicas constituyan un eje fortalecedor del desarrollo. La Ley 1804 establece la importancia de operar de acuerdo con los referentes conceptuales, pedagógicos y metodológicos 
mediante procesos intencionales, estructurados y pertinentes, a lo que el Decreto 1075 sugiere orientar el currículo para primera infancia a promover un desarrollo integral y multidimensional que responda a las necesidades formativas de la infancia, de acuerdo con su contexto. Para el Plan Decenal dichos aspectos curriculares deben ser adecuados, flexibles y encaminados hacia la primera infancia, en tanto que el Conpes 109 señala que los modelos y las mediaciones pedagógicas deben responder al propósito de construir propuestas curriculares dirigidas a la formación integral, desde un enfoque por competencias.

Estos componentes pedagógicos deben verse reflejados en unas acciones, descritas en el eje «Estrategias, planes, proyectos y mediaciones pedagógicas», las cuales han de conducir a promover el desarrollo de todas las dimensiones por medio de actividades planificadas y progresivas, de carácter transversal, multidimensional, vivencial, espontáneo y productivo, que incluyan y reconozcan las necesidades educativas de la población. Este ejercicio, visto como acción innovadora y transformadora, debe enmarcarse en acciones planificadas que integren la lúdica, la creatividad y la autonomía, y que promuevan un acercamiento a la ciencia, la cultura y el deporte por medio de escenarios y entornos de interacción social.

Una de las iniciativas para afianzar y articular los procesos de aprendizaje son los derechos básicos de aprendizaje (DBA) para transición, diseñados en el marco de la Ley 1804, con los cuales se espera orientar a los educadores infantiles en la construcción de experiencias y ambientes a través de mediaciones pedagógicas, las cuales son definidas como «acciones intencionadas, diseñadas y planificadas que facilitan la relación de los aprendizajes estructurantes y los desarrollos propios de los niños y niñas que promueven la confianza en sí mismos, su autonomía, la construcción de identidad, la libre expresión y comunicación, su creatividad y curiosidad, su pensamiento crítico, y el ejercicio de su ciudadanía» (Ministerio de Educación Nacional, 2016a, p. 6).

En lo referente a las prácticas educativas, para el Decreto 2450 (Ministerio de Educación Nacional, 2015a) y la Resolución 2041 (Ministerio de Educación Nacional, 2016b), estas deben sustentarse en unas bases conceptuales firmes que permitan posicionar el escenario escolar como centro de desarrollo social y cultural. Respecto a la evaluación en la educación infantil, Zabalza (2017) propone flexibilizar el concepto de evaluación, «incluyendo en él todas aquellas actuaciones y dispositivos que nos permitan conocer, reconocer, analizar y valorar las cosas que hacemos y el efecto que van teniendo en los niños con los que trabajamos» (p. 9). Para las políticas analizadas, manifiesta que la evaluación ha de ser acorde con las necesidades y particularidades del contexto sociocultural, que haga énfasis en el seguimiento y acompañamiento al desarrollo integral, sin que esta tenga un carácter aprobatorio.

Igualmente, se espera que el proceso de formación del educador infantil le permita participar en acciones de investigación educativa que aporten a la gestión del conocimiento e innovación en el campo disciplinar y que fomenten un interés por la ciencia. Otros aspectos fundamentales para la formación docente (Metas 2021) son la participación y creación de redes académicas de producción intelectual en grupos y semilleros de investigación social y ambiental (Plan Decenal), la formación para la investigación, así como el aporte a la gestión del conocimiento a partir de la investigación disciplinar y pedagógica (Ley 1804), que contemple un carácter interdisciplinario y genere un impacto social determinante (Decreto 2450).

\section{Saberes didácticos}

En esta categoría se reconocen tres ejes: la construcción de ambientes de aprendizajes necesarios y propicios para la formación integral de la infancia, la incorporación de las TIC en los procesos de enseñanza y las dimensiones potenciales en el desarrollo de la primera infancia, señaladas por la Ley 1804 como pilares de la educación infantil (figura 6). 
Figura 6. Categoría «Saberes didácticos»

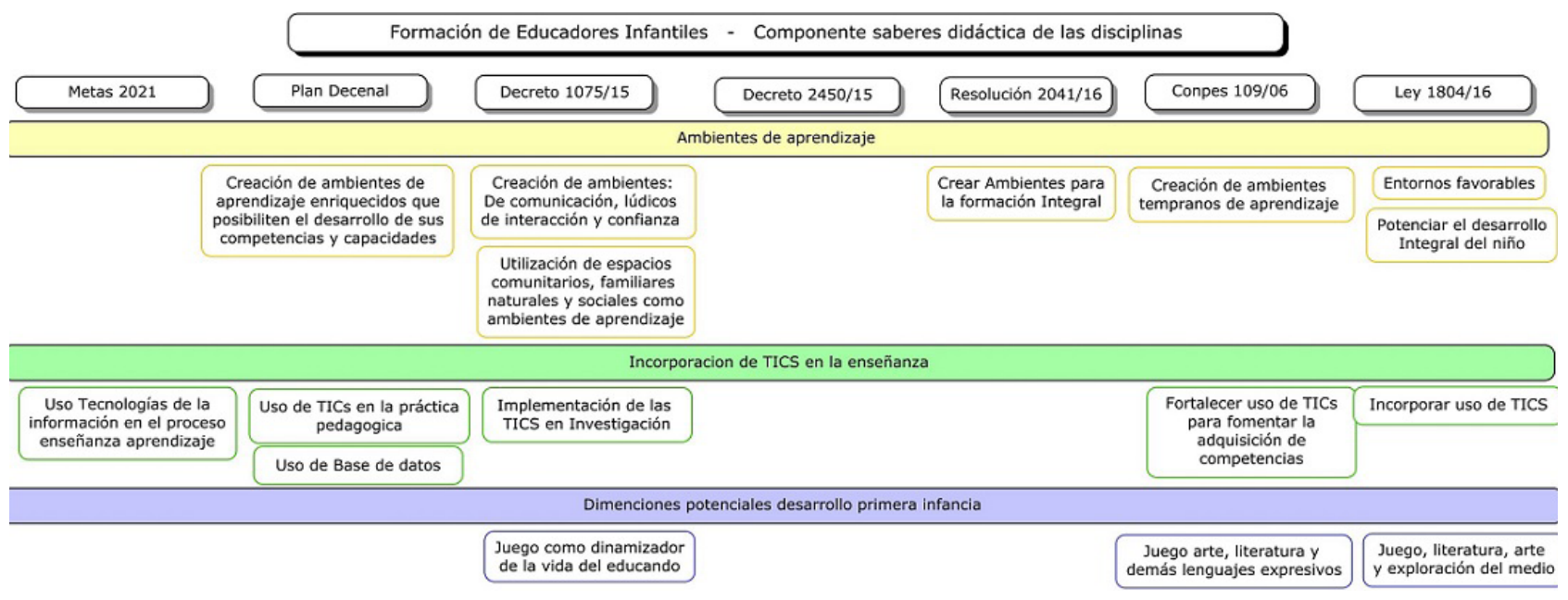

El sentido de integrar el eje «Ambientes de aprendizaje» dentro de los saberes didácticos y no en los pedagógicos está en la naturaleza de la educación infantil y en el papel que cumple la interacción con el medio para un desarrollo integral privilegiado en los primeros años de vida (Centro de Estudios en Desarrollo Infantil de Harvard, 2011; Diamond, 2013). La educación infantil está contemplada desde el desarrollo de las dimensiones del ser humano, por lo que el diseño, la creación y la proyección de los ambientes del aprendizaje estarán orientados a favorecer dichos desarrollos y a ser claves para la didáctica de esta disciplina.

Las políticas analizadas coinciden en que la creación de ambientes de aprendizaje son el centro para fomentar acciones encaminadas a la formación integral y multidimensional de la infancia (Plan Decenal), especifican que dichos ambientes han de ser escenarios de comunicación, lúdica e interacción y confianza, que conduzcan a la utilización de espacios comunitarios, familiares, naturales y sociales (Decreto 1075). En el Conpes 109 se dan orientaciones para la construcción de dichos ambientes, en tanto que en la Ley 1804 se consideran estos entornos como favorables para potenciar el desarrollo y la integralidad de los procesos de aprendizaje de la infancia.

Se ha contemplado la categoría «Dimensiones potenciales para el desarrollo en la primera infancia», en la cual se presentan «las actividades rectoras de la primera infancia», descritas en la política de Estado para la primera infancia (Ley 1804), con la premisa de que la primera infancia es un momento del ciclo vital en que «aprenden a encontrar múltiples y diversas maneras de ser niñas y niños, mientras disfrutan de experiencias de juego, arte, literatura y exploración del medio» (Congreso de Colombia, 2016, p. 12); se afirma que son estas experiencias —el juego, el arte, la literatura y la exploración del medio- las que deben tener un lugar protagónico en la educación inicial, «dado que potencian el desarrollo de las niñas y los niños desde las interacciones y relaciones que establecen en la cotidianidad» (Ministerio de Educación Nacional, 2015b, p. 10).

El Conpes 109 y la Ley 1804 son enfáticos al afirmar que estas actividades rectoras, fuera de los lenguajes expresivos, son ejes potenciadores del desarrollo integral infantil, premisas compartidas por las demás políticas estudiadas: en el Decreto 1075 se relaciona el juego como dinamizador de la vida del educando; en las Metas educativas 2021 se destacan la importancia del juego y del descubrimiento, el fomento de las experiencias comunicativas y estéticas en la educación en la primera infancia, y se propone desarrollar «programas de educación infantil en los que el arte y el juego tengan una función principal como medio para potenciar la creatividad, fomentar la identidad cultural y buscar la adquisición de capacidades, competencias y destrezas en edades tempranas del desarrollo» (Organización de Estados Iberoamericanos, 2008, p. 238). 


\section{POLÍTICAS PÚBLICAS Y POLÍTICAS EDUCATIVAS PARA LA PRIMERA INFANCIA: DESAFIOS DE LA FORMACIÓN DEL EDUCADOR INFANTIL}

\section{Saberes transversales}

Incluye los saberes que forman parte fundante y transversal de la cotidianidad del maestro y traspasan los demás saberes en su práctica (figura 7). Las políticas coinciden en la importancia de construir espacios de formación en valores, promover el respeto, la tolerancia, la cooperación, la autoestima, y que apunten hacia la democracia y una cultura de paz; la formación en ciudadanía y la paz desde la primera infancia pretenden enriquecer los procesos de aprendizaje y de interacción social en los que se logren el reconocimiento de identidades y el fortalecimiento de la autonomía. A la vez, se reconocen las acciones pertinentes para ofrecer orientación efectiva y mecanismos de participación a la familia y la comunidad en los procesos educativos que permitan sensibilizarla hacia la importancia de propiciar un desarrollo integral desde la primera infancia.

Figura 7. Categoría «Saberes transversales»

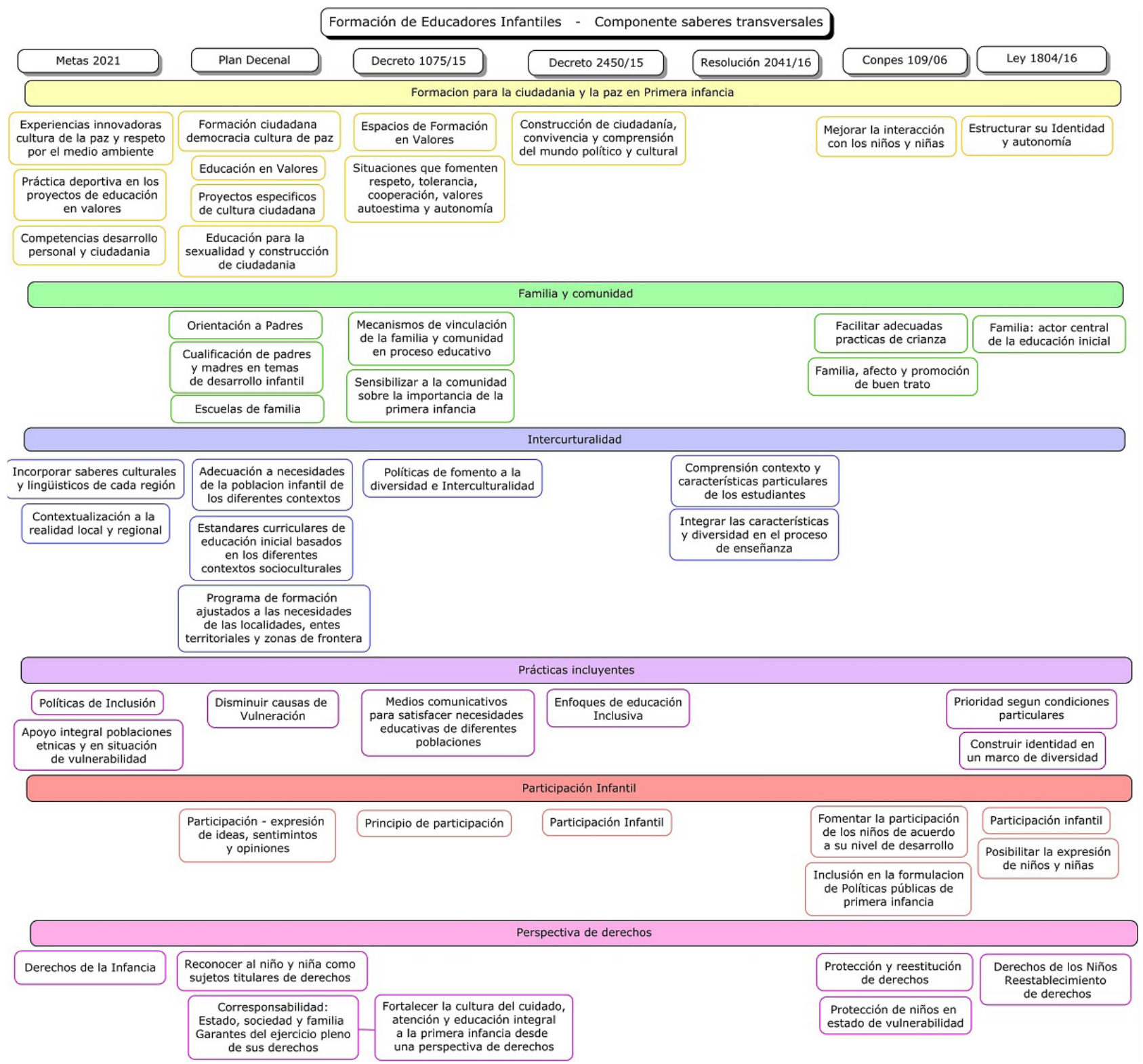


Por su parte, en el eje «Interculturalidad»se destaca la incorporación de los saberes culturales y lingüísticos de cada región que presenten un enfoque contextualizado y la adecuación a las necesidades de la población infantil. Esto último resuena en las prácticas incluyentes como mecanismo que garantice la integración de las comunidades étnicas (Metas 2021), la disminución de la violencia y la vulneración de los derechos (Plan Decenal), la integración de medios de comunicación alternativos (Decreto 1075), de modo que se logre priorizar y satisfacer las necesidades particulares de cada grupo social, en la medida en que se vaya construyendo una identidad en un marco de diversidad y respeto a la diferencia (Ley 1804).

Está claro que «las propuestas educativas para la formación de formadores en educación infantil tienen explícito un compromiso con los niños y las niñas como sujetos de derechos» (Ochoa \& Nossa-Núñez, 2013, p. 71); en esta perspectiva de derechos se quiere que el docente reconozca a las niñas y los niños como sujetos titulares de derechos, actúe como garante de estos, favorezca su protección y restablecimiento, y contemple a los estudiantes como sujetos activos y constructores de conocimiento, como interlocutores válidos. En este sentido, se espera que el docente no solo vele por los derechos de la niñez, sino que promueva la participación infantil, según su nivel de desarrollo, desde todas las esferas y posibilidades que permita empoderar y legitimar a la infancia como grupo social con voz e identidad propia, de manera que su voz se tome en cuenta en la formulación de las políticas en primera infancia. Para Durán-Strauch (2017), las políticas de infancia deben implicar la actuación política de los niños y niñas; más allá de la actuación del adulto en representación de las necesidades de la niñez, las políticas deben asumir en su formulación la ciudadanía de niños y niñas transformadores de su propia identidad, con posibilidades de ejercer una influencia notable en la toma de decisiones políticas.

\section{Discusión}

Actualmente hay toda una suerte de posicionamientos políticos, encaminados a mejorar condiciones de la educación en el mundo, como la Declaración de Incheon «Metas educativas 2030» (Unesco, 2015), en la que se postula la educación como el motor principal del desarrollo. A estos esfuerzos se suma la resonancia internacional respecto a la primera infancia como un periodo clave para el desarrollo. Colombia se ha sintonizado con estas iniciativas por medio de políticas y lineamientos de políticas tanto en materia de educación, como de atención integral a la primera infancia.

En respuesta a estas políticas nacionales, a escala regional, con la política pública de infancia y adolescencia del municipio de Ibagué (Alcaldía de Ibagué, 2016) se pretende posicionar la educación inicial en el primer lugar de interés para la política educativa del municipio, con acciones encaminadas a garantizar el acceso a una educación inicial de calidad, la ampliación de cobertura con énfasis en zonas rurales y marginales urbanas, la articulación de la educación inicial y la educación preescolar, y la sensibilización de las familias en la importancia de la atención a la educación inicial. Con este fin, la política reconoce la necesidad de una cualificación permanente de los agentes educativos, mejorar los ambientes educativos, al igual que vincular otras disciplinas, como la educación física y artes, a la educación inicial.

A pesar de estas iniciativas políticas, su seguimiento no ha mostrado cambios sustanciales en las realidades de los niños y niñas. Según el análisis hecho por Rozo y Vargas-Trujillo (2018), estas políticas no se vinculan con la realidad de los territorios (propensos a la realización de eventos impredecibles y dinámicos), pues persiste una ausencia de procesos de interacción y comunicación con los sujetos, escasa participación de los niños y niñas en las distintas etapas de la formulación de políticas, carencia de compromiso institucional por la continuidad de las intervenciones y falta de los recursos suficientes para su sostenibilidad.

En esta dinámica, el maestro se posiciona como una de las bisagras entre las metas trazadas por dichas políticas y la puesta en escena de su implementación; por tal motivo, la formación del educador 
infantil se ha postulado como una gran apuesta a la hora de materializar la atención y la educación infantil. La presente investigación permitió dar cuenta de los retos y demandas a la formación de los educadores infantiles, que se desprenden de las políticas seleccionadas. Estas últimas se enfocan en elementos estructurantes, como el cuidado y la crianza, salud, alimentación y nutrición, articulación con la educación primaria, recreación, participación y ejercicio de la ciudadanía. Actúan como un marco legal e institucional que pretende orientar la construcción de estrategias en los ámbitos local, institucional y nacional, que tienen, hoy en día, el compromiso de superar las formas convencionales de la gestión y propender a la especificidad, contextualidad y diversidad de los grupos poblacionales. En conjunto, la atención y la educación en la primera infancia despliegan atributos expresos en acciones en los entornos de actuación y desarrollo de la vida de los niños y niñas en condiciones humanas, sociales y materiales.

En consecuencia, los retos en la formación del maestro son múltiples y de gran envergadura: la capacidad de activar las rutas de atención articuladas a esfuerzos interinstitucionales e intersectoriales, la participación activa en la formulación, implementación y evaluación de dichas políticas, como acción esencial para incrementar la demanda pública por educación y un factor clave para el éxito de las políticas (Blanco, 2012).

Aun cuando las políticas no expresan necesariamente de manera explícita cuáles son los saberes específicos en que se debe formar el educador infantil, el análisis hecho permitió reconocerlos a partir de los retos que suponen dichas políticas. Una de las dimensiones emergentes fueron los saberes disciplinares, los cuales muestran saberes particulares claves con respecto a los docentes de otras disciplinas. Por un lado, la demarcación de estos saberes está relacionada íntimamente con la posibilidad de enseñabilidad de una disciplina, pero en la educación infantil, estos referentes disciplinares presentan bordes más difusos. Investigaciones como la de Morales-Saavedra, QuilaqueoRapimán y Uribe-Sepúlveda (2010) estudiaron los saberes disciplinares del educador infantil, desde la perspectiva el maestro, encontrando un énfasis en las neurociencias, los factores genéticos, el desarrollo emocional y motriz en los primeros años del ser humano, elementos en común con las políticas analizadas.

Si bien, disciplinalmente, se espera que el docente cuente con un bagaje conceptual actualizado en relación a al desarrollo integral de la infancia y a las tendencias propias de su disciplina, los mayores retos del educador están en propiciar acciones conducentes a reconocer los ritmos de aprendizaje de los niños y niñas, garantizar la estimulación en sus diferentes dimensiones, reconocer los cambios cualitativos y cuantitativos, así como apoyar al detección temprana de alteraciones del desarrollo, esto último encaminado además a propender por la prevención y promoción de la salud en esta etapa crucial en el desarrollo del niño, máxime cuando sus mecanismos de autocuidado aún son incipientes a esta edad. Ahora bien, al educador infantil le corresponde conocer e implementar acciones conducentes a los propósitos de las políticas de primera infancia, así como se le invita a respaldar su diseño y gestión. Con una responsabilidad crucial en favorecer un tránsito articulado y oportuno entre la educación infantil y la educación primaria.

Por otro lado se pueden diferenciar entre los retos para la formación del maestro de primera infancia, ciertos saberes pedagógicos, definidos por Morales et al. (2010) como una construcción propia de cada sujeto, que surge «como resultado de las interacciones entre sus disposiciones internas y el contexto cultural y social de manera activa y participativa; esto le permite organizar, interpretar y reestructurar el conocimiento con la experiencia, los saberes previos y la información que de diversas fuentes recibe» (p. 51). La formación de estos saberes, por tanto, no se reducen a los contenidos curriculares de un programa de formación, si no que ha de proveerse las oportunidades de aprendizaje en un ejercicio activo con la realidad.

En relación con este problema, Vélez-Álvarez, Jaramillo-Ángel y Giraldo-Osorio (2018) plantean que, en la formación de los futuros profesionales, la relación curricular entre los desarrollos teóricos y la práctica «debe ser permanente, e incorporar una dimensión investigativa que demuestre los logros en comprensión de conceptos y capacidad de relacionarlos con la práctica cotidiana y con 
las realidades micro y macro del medio donde se realiza la práctica» (p. 180). Gorostiaga (2017), por otro lado, enfatiza en que dicha formación en investigación, además de ayudar a construir nuevo conocimiento y propender a su propia formación y especialización de sus saberes, debe garantizar que el docente desarrolle conocimientos que le permitan hacer una lectura y análisis de las políticas educativas «con perspectiva histórica y en el marco de los procesos sociales, económicos y políticos nacionales y globales, elementos fundamentales para entender el origen y las implicancias de las políticas» (p. 42).

Para las políticas estudiadas, el educador infantil debe formarse en referentes pedagógicos, conocer los estándares curriculares de educación inicial, hacer las adecuaciones que permitan reconocer las características particulares de los niños y niñas, saber integrarlas a su proceso de aprendizaje, formular estrategias, proyectos y acciones pedagógicas pertinentes, propugnar la inclusión y la superación de las barreras de aprendizaje, crear prácticas pedagógicas innovadoras que pongan a la escuela como centro de desarrollo social y cultural, y formular acciones de evaluación, más allá de su carácter probatorio, que permitan apreciar los avances en el desarrollo integral del niño, sus necesidades y mejoramiento de la práctica educativa.

Los saberes didácticos de las disciplinas, en palabras de Lenis (2017), refieren a «saber qué hacer con los conocimientos, saber innovar, saber seleccionar e identificar las mejores formas y materiales de trabajar»; según el autor, estas serían competencias que se fundamentarían en investigaciones de la didáctica, no de la pedagogía. Este componente se pudo evidenciar en los resultados con énfasis en el papel protagónico de la construcción de entornos y situaciones de aprendizaje, como entornos favorables para el pleno desarrollo de la primera infancia, espacios que impliquen además la comunidad, la familia, la escuela y la relación con el ambiente; adicionalmente, todo esto integra las tecnologías de la información y la comunicación.

Con imperioso énfasis, en algunas políticas nacionales se han subrayado el juego, el arte, la literatura y la exploración del entorno como «actividades rectoras de la primera infancia», y como dimensiones inherentes y potenciales del desarrollo de la primera infancia, para que antes de actuar como herramientas o estrategias pedagógicas para lograr otros aprendizajes, en sí mismas posibiliten aprendizajes (Córdoba-Garcés, Hernández-Monsalve, Palacio-Chavarriaga, \& Tobón-Moreno, 2017). Por tanto, el Ministerio de Educación las postula como pilares de una «cultura de la educación inicial» en el marco de la atención integral.

Por último, se han reconocido unos saberes transversales, que atraviesan la cotidianidad del educador infantil, el reconocimiento de los niños y niñas como sujetos sociales de derecho, el ser garante de derechos de la infancia y favorecer la disminución de las condiciones de vulnerabilidad, el reconocer a los niños y niñas como interlocutores válidos, a los cuales se les debe garantizar y estimular su capacidad de participación social y política, una actitud incluyente que disminuya las situaciones de exclusión y discriminación. Del educador infantil se espera que contemple la interculturalidad como una columna estructural de la identidad colombiana y, por consiguiente, de una educación situada y contextualizada que integre las particularidades de los territorios a su práctica docente, que promueva la formación para la ciudadanía y la paz, así como que se le demandan acciones conducentes a la articulación entre la familia, la comunidad y la escuela.

Del docente también se espera que participe en redes académicas, que vele por sus propios procesos de desarrollo profesional, que se cualifique y especialice. En perspectiva, los retos en la formación del educador infantil son colosales y con cada política emergente se hacen de mayor envergadura, sin que esto se vea reflejado necesariamente en un mayor reconocimiento social, remuneración económica por su trabajo, condiciones tangibles indispensables para dar respuesta a estos retos o posibilidades de desarrollo para los maestros.

Este panorama arrojado por la investigación se presenta como una invitación a pensar la educación para la primera infancia, desde el lugar del educador; no necesariamente desde el lugar de las políticas públicas, sino desde el lugar en que acontece la cotidianidad del docente que emprende día tras día su rol como agente para el desarrollo integral de los más pequeños. Así las cosas, el 
reto fundamental está en trascender el ejercicio de formulación, comprensión y puesta en marcha de las políticas y lineamientos de políticas; es decir, claro que el reto también está allí, pero sería insuficiente si no se contemplara en clave de realidad, y con esto habría que referirse tanto a las múltiples realidades de los niños y niñas, como también a las realidades de los numerosos docentes de primera infancia en Colombia.

La investigación cumplió con su expectativa de propiciar una reflexión sobre los retos y desafíos de la formación del educador infantil a la luz de las políticas públicas y educativas más representativas en el tema, al igual que el panorama que se representa para los programas de formación de maestros. En este estudio se visibilizan los encuentros y desencuentros entre las políticas públicas y educativas, a la vez que se contrastan las aspiraciones con la realidad de la escuela colombiana, una realidad carente de condiciones materiales, sociales, financieras y políticas que actúen en consonancia con las metas propuestas, a propósito de tener a su cargo la responsabilidad de formar la etapa más crucial del desarrollo humano.

\section{Lista de referencias}

Alcaldía de Ibagué. (2016). La política pública de infancia y adolescencia del municipio de Ibagué (Tolima). Recuperado de: https://cimpp. ibague.gov.co/politica-publica/.

Alfonzo, I. M. (1994). Técnicas de investigación bibliográfica. Caracas: Contexto Editores.

Ancheta-Arrabal, A. (2008). Hacia una nueva concepción de la educación de la primera infancia como derecho: avances y desafíos globales. Iberoamericana de Educación, 47, 5-25.

Andréu-Abela, J. (2000). Las técnicas de análisis de contenido: una revisión actualizada. Fundación Centro Estudios Andaluces, Universidad de Granada [revista virtual], 10(2), 1-34. Recuperado de: http://public.centrodeestudiosandaluces.es/pdfs/S200103.pdf.

Ávalos, B. (2007). El desarrollo profesional continuo de los docentes: lo que nos dice la experiencia internacional y de la región latinoamericana. Pensamiento Educativo, 41(2), 207-222.

Blanco, R. (2012). Una atención y educación de calidad en la primera infancia puede hacer la diferencia. Revista Docencia, 48, 4-17.

Buitrago-Rodríguez, N. E. (2015). Informe nacional sobre docentes para la educación de la primera infancia: Colombia. Documento de trabajo preparado para el proyecto estratégico regional sobre docentes para América Latina y el Caribe. Recuperado de: http://ceppe.uc.cl/images/contenido/ publicaciones/proyecto-estrategico-regional/2012/Informe-Primera-Infancia-Colombia.pdf.

Camargo-Abello, M., \& Castro-Rojas, A. (2013). Estrategia de atención integral a la primera infancia: fundamentos políticos, técnicos y de gestión. Bogotá, D. C.: Presidencia de Colombia.

Carneiro-Sarturi, R. (2012). Políticas públicas para la formación de profesores: repercusiones en el currículum del curso de pedagogía [versión electrónica]. Estudios y Experiencias en Educación, 12(21), 15-31. Recuperado de:

http://www.redalyc.org/articulo.oa? id=243124125001.

Castro-Rojas, A. L. (2008). Formación de docentes y educadores en educación infantil: una apuesta clave para el desarrollo integral de la primera infancia. Bogotá, D. C.: Organización de Estados Iberoamericanos. Recuperado de: www.oei.es/historico/idie/educacioninfantil.pdf.

Castro-Rojas, A. L., Cuéllar-Argote, C., \& Londoño, C. (2012). Conceptualizaciones sobre políticas públicas. Revista Dos Mil Tres Mil, 3(14), 123-138.

Centro de Estudios en Desarrollo Infantil de la Universidad de Harvard. (2011). Building the Brain's «Air Traffic Control» System: How early experiences shape the development of executive function. Working Paper, 11. Recuperado de: http://www.developing child.harvard.edu.

Congreso de Colombia. (1994). Ley general de educación [Ley 115]. Bogotá, D. C.: Diario Oficial, 41214.

Congreso de Colombia. (2006). Código de Infancia y Adolescencia [Ley 1098]. Bogotá, D. C.: Diario Oficial, 46446. 
Congreso de Colombia. (2016). Política de Estado para el desarrollo integral de la primera infancia De Cero a Siempre [Ley 1804]. Bogotá, D. C.: Diario Oficial, 49953.

Córdoba-Garcés, L. M., Hernández-Monsalve, P. I., Palacio-Chavarriaga, C., \& Tobón-Moreno, J. A. (2017). Pilares de la educación inicial: mediadores para el aprendizaje. Funlam Journal of Students's Research, (2), 86-94. doi:10.21501/25007858.2582.

Departamento Nacional de Planeación. (2007). Política pública nacional de primera infancia [Conpes 109]. Bogotá, D. C.: Diario Oficial.

Diamond, A. (2013). Activities and programs that improve children's executive functions. Current Directions in Psychological Science, 21(5), 335-341. Recuperado de: http:/journals.sagepub. com/doi/pdf/ 10.1177/0963721412453722.

Durán-Strauch, E. (2017). Derechos de niños y niñas: del discurso a la política local. Revista Latinoamericana de Ciencias Sociales, Niñez y Juventud, 15(2), 879-891. doi:10.11600/169271 5x.1520623062016.

Espinoza, O. (2009). Reflexiones sobre los conceptos de «política», políticas públicas y política educacional [versión electrónica]. Archivos Analíticos de Políticas Educativas, 17(8). Recuperado de: http://www.redalyc.org/articulo.oa?id=275019727008.

Fabián, H., \& Dunlop, A. W. (2006). Outcomes of good practice in transition processes for children entering primary school. París: Unesco. Recuperado de: http://unesdoc.unesco.org/ images/0014/001474/147463e.pdf.

Fernández-Chávez, F. (2002). El análisis de contenido como ayuda metodológica para la investigación [versión electrónica]. Revista de Ciencias Sociales, 2(96), 35-53. Recuperado de: http://www. redalyc.org/pdf/153/15309604.pdf.

Fuentes de la Roa, L. (2008). La formación y capacitación de los educadores de la atención a la primera infancia: historia y apuestas. En A. L. Castro-Rojas (Comp.) Formación de docentes y educadores en educación infantil: una apuesta clave para el desarrollo integral de la primera infancia (pp. 65-73). Bogotá, D. C.: Organización de Estados Iberoamericanos.

Gorostiaga, J. M. (2017). La formación de investigadores en el campo de la política educativa: una mirada regional. Revista de la Educación Superior, 46(183), 37-45. Recuperado de: https://doi. org/10.1016/j.resu.2017.06.001.

Grediaga-Kuri, R. (2011). Relevancia y complejidades del análisis de políticas públicas en educación. Revista de Investigación Mexicana, 16(50), 679-686.

López, F. (2002). El análisis del discurso como método de investigación. XXI Revista de educación, (4), 167-180. Recuperado de:

https://dialnet.unirioja.es/servlet/articulo? codigo $=309707$

Lenis, J. D. (2017). Del saber pedagógico al saber didáctico. Recuperado de: https://www.magisterio. com.co/articulo/del-saber-pedagogico-al-saber-didactico.

Marulanda-Hidalgo, L. (2013). Comprensiones sobre infancia en la política pública de educación para la primera infancia en Colombia, 1968-2010. (Tesis doctoral). Universidad Santo Tomás, Bogotá, Colombia. Recuperado de:

http://repository.usta.edu.co/bitstream/handle/11634/3402/Marulandalynn2016.pdf.

Ministerio de Educación Nacional. (1998). Serie Lineamientos curriculares: Preescolar. Bogotá, D. C.: Ministerio de Educación Nacional. Recuperado de:

http://www.mineducacion.gov.co/1759/articles-339975_recurso_11.pdf.

Ministerio de Educación Nacional. (2006). Plan Decenal de Educación. Pacto social por la educación 2006-2016. Bogotá, D. C.: Ministerio de Educación Nacional. Recuperado de: http://www. sedbogota.edu.co/archivos/nuestra_entidad/version_final_pnde_interactiva.pdf.

Ministerio de Educación Nacional. (2012). Documento base para la construcción de lineamientos pedagógicos y curriculares para la educación inicial. Bogotá, D. C.: Ministerio de Educación Nacional. 
Ministerio de Educación Nacional. (2014a). La cualificación del talento humano que trabaja con primera infancia: serie de orientaciones pedagógicas para la educación inicial en el marco de la atención integral. Documento N. ${ }^{\circ}$ 19. Bogotá, D. C.: Ministerio de Educación Nacional.

Ministerio de Educación Nacional. (2014b). Políticas y sistema colombiano de formación y desarrollo profesional docente. Bogotá, D. C.: Ministerio de Educación Nacional. Recuperado de: http:// www.mineducacion.gov.co/cvn/1665/articles-208603_archivo_pdf.

Ministerio de Educación Nacional. (2014c). Sentido de la educación inicial: serie de orientaciones pedagógicas para la educación inicial en el marco de la atención integral. Documento N. 20. Bogotá, D. C.: Ministerio de Educación Nacional.

Ministerio de Educación Nacional. (2015a). Condiciones de calidad para el otorgamiento y renovación del registro calificado de los programas académicos de licenciatura y los enfocados a la educación [Decreto 2450]. Bogotá, D. C.: Diario Oficial.

Ministerio de Educación Nacional. (26 de marzo de 2015a). Decreto único reglamentario del sector de la educación [Decreto 1075]. Bogotá, D. C.: Diario Oficial.

Ministerio de Educación Nacional. (2016a). Derechos básicos de aprendizaje: transición. Bogotá, D. C.: Ministerio de Educación Nacional. Recuperado de:

http://aprende.colombiaaprende.edu.co/ckfinder/userfiles/files/DBA\%20Transici\%C3 \%B3n. pdf.

Ministerio de Educación Nacional. (2016b). Características especificas de calidad de los programas de licenciatura para la obtención, renovación o modificación del registro calificado [Resolución 2041]. Bogotá, D. C.: Diario Oficial.

Morales-Saavedra, S., Quilaqueo-Rapimán, D., \& Uribe-Sepúlveda, P. (2010). Saber pedagógico y disciplinario del educador de infancia. Un estudio en el sur de Chile. Perfiles Educativos, 32(130), 49-66. Recuperado de:

http://www.scielo.org.mx/pdf/peredu/v32n130/v32n130a4.pdf.

Moreno-Olmedilla, J. M. (2006). Profesorado de secundaria y calidad de la educación: un marco de opciones políticas para la formación y el desarrollo profesional docente. Profesorado. Revista de Currículum y Formación del Profesorado, 10(1). Recuperado de: http://www.redalyc.org/ articulo.oa?id=56710104.

Myers, R. (2015). Desarrollo infantil temprano en México: avances y retos. Boletín Médico del Hospital Infantil de México, 72(62), 359-361. doi:10.1016/j.bmhimx.2015.11.001.

Navío-Gámez, A. (2007). El resultado de los programas de formación de formadores: análisis comparativo de dos realidades institucionales [versión electrónica]. Profesorado. Revista de Currículum y Formación del Profesorado, 11(2). Recuperado de:

http://www.ugr.es/ recfpro/rev112COL1.pdf.

Ochoa, S. I., \& Nossa-Núñez, L. (2013). La infancia desde las apuestas formativas en educación y la política pública [versión electrónica]. Revista Infancias Imágenes, 12(1), 70-77. doi:10.14483/ issn. 1657-9089.

Organización de Estados Iberoamericanos. (2008). Metas 2021: la educación que queremos para la generación de bicentenarios. Madrid: Organización de Estados Iberoamericanos.

Organización de Estados Iberoamericanos. (2011). Congreso mundial. La educación de la primera infancia: "Los tres primeros años de vida del niño y la niña». Puebla: Organización de Estados Iberoamericanos. Recuperado de: http://portal.oas.org.

Organización de Estados Iberoamericanos. (2013). Miradas sobre la educación en Iberoamérica. Desarrollo profesional docente y mejora de la educación. Madrid: Organización de Estados Iberoamericanos.

ONU. (2005). Observación General N. ${ }^{\circ}$ 7. Realización de los derechos del niño en la primera infancia. Recuperado de:

http://www.acnur.org/t3/fileadmin/Documentos/BDL/2010/8019.pdf?view=1. 
Oszlak, O., \& O’Donnell, G. (1995). Estado y políticas estatales en América Latina: hacia una estrategia de investigación. Redes, 2(4), 99-118.

Pérez-Escamilla, R. (2017). Estancias infantiles y desarrollo infantil en México: avances y retos. Boletín Médico del Hospital Infantil de México, 74(2), 84-85. doi:10.1016/j.bmhimx.2017.01.005.

Pérez-Escamilla, R., Rizzoli-Córdoba, A., Alonso-Cuevas, A., \& Reyes-Morales, H. (2017). Boletín Médico del Hospital Infantil de México, 74(2), 86-97. doi:10.1016/j.bmhimx.2017.01.007.

Pineda-Báez, N. Y., Garzón-Rodríguez, J. C., Bejarano-Novoa, D. C., \& Buitrago-Rodríguez, N. E. (2015). Aportes para la educación inicial: saberes construidos por el Proyecto Pedagógico Educativo Comunitario. Revista Latinoamericana de Ciencias Sociales, Niñez y Juventud, 13(1), 263-278. doi: 10.11600/1692715x.13115050914.

Rodríguez-Gómez, H. M. (2010). La escuela de otro(s) modo(s). Revista Educación y Pedagogía, (56). Recuperado de:

http://aprendeenlinea.udea.edu.co/revistas/index.php/revistaeyp/article/view/9815.

Rojas-Betancur, H. M. (2008). La importancia de las políticas públicas de formación en investigación de niños, niñas y jóvenes en Colombia, para el desarrollo social [versión electrónica]. Revista Latinoamericana de Ciencias Sociales, Niñez y Juventud, 6(2), 885-906. Recuperado de: http:// www.scielo.org.co/pdf/rlcs/v6n2/v6n2a14.pdf.

Roth-Deubel, A. (2007). Enfoques y teorías para el análisis de las políticas públicas, cambio de la acción pública y transformaciones del Estado. Ensayos sobre Políticas Públicas. Bogotá, D. C: Universidad Externado de Colombia.

Rozo, N., \& Vargas-Trujillo, Z. (2018). Análisis de política pública de infancia y adolescencia, 2011-2021, en Bogotá, Colombia. Desafíos, 30(2). doi:10.12804/revistas.urosario.edu.co/ desafios/a.5325.

Simarra-Torres, J. (2010). Formación de agentes educativos institucionales y comunitarios en Colombia. Estrategias claves de la educación inicial. Recuperado de: http://goo.gl/cu0kK4.

Unesco. (1990). Conferencia Mundial sobre Educación para Todos. Declaración Mundial sobre Educación para Todos. Jomtien: Unesco. Recuperado de: http://unesdoc.unesco.org/ images/0012/001275/127583s.pdf.

Unesco. (2000). Foro Mundial sobre Educación para Todos. Marco de Acción de Dakar: Educación para Todos. Dakar: Unesco. Recuperado de: http://unesdoc.unesco.org/images/0012/001211/121117s. pdf.

Unesco. (2015). Declaración de Incheon y Marco de Acción para la realización del Objetivo de Desarrollo Sostenible 4. Garantizar una educación inclusiva y equitativa de calidad y promover oportunidades de aprendizaje permanente para todos. Recuperado de: http://unesdoc.unesco. org/images/0023/002338/233813m.pdf.

Unesco. (2016a). Estado del arte y criterios orientadores para la elaboración de políticas de formación y desarrollo profesional de docentes de primera infancia en América Latina y el Caribe. Santiago de Chile: Unesco. Recuperado de: http://unesdoc.unesco.org/images/0024/002451/245157s.pdf.

Unesco. (2016b). Perspectivas sobre políticas docentes en América Latina y el Caribe: aprendizajes de la estrategia regional sobre docentes 2011-2016. Santiago de Chile: Unesco.

Unicef. (1990). Cumbre Mundial a favor de la Infancia. Nueva York: Unicef. Recuperado de: https:// www.unicef.org/spanish/specialsession/about/world-summit.htm.

Vélez-Álvarez, C., Jaramillo-Ángel, C. P., \& Giraldo-Osorio, A. (2018). Docencia-servicio: responsabilidad social en la formación del talento humano en salud en Colombia. Educación Médica, 19(2), 179-186. doi:10.1016/j.edumed.2017.08.002.

Zabalza, M. A. (2017). Evaluar en educación infantil. Revista Latinoamericana de Educación Infantil, 6(1-2), 9-14. Recuperado de:

http://www.usc.es/revistas/index.php/reladei/article/view/4995/5356. 
Zambrano-Leal, A. (2012). Formación docente en Colombia. Arqueología de la política pública y del escenario internacional. Educere, 16(54), 11-19.

Zapata-Ospina, B. E., \& Restrepo-Mesa, J. H. (2013). Aprendizajes relevantes para los niños y las niñas en la primera infancia. Revista Latinoamericana de Ciencias Sociales, Niñez y Juventud, 11(1), 217-227. doi:10.11600/1692715x.11114270712 